\title{
Parasites and epilepsy: understanding the determinants of epileptogenesis
}

\author{
Samuel A. Angwafor ${ }^{a}$, Gail S. Bell ${ }^{a}$, Alfred K. Njamnshi ${ }^{\text {c, e }}$, Gagandeep Singh ${ }^{\text {a,d }}$, Josemir W. \\ Sander ${ }^{a, b}$ \\ a. NIHR University College London Hospitals Biomedical Research Centre, UCL Queen Square \\ Institute of Neurology, London WC1N 3BG and Chalfont Centre for Epilepsy, \\ Buckinghamshire, United Kingdom \\ b. Stichting Epilepsie Instelligen Nederland (SEIN), Netherlands \\ c. Neurology Department, Central Hospital Yaoundé/Faculty of Medicine and \\ Biomedical Sciences (FMBS), The University of Yaoundé 1 \\ d. Department of Neurology, Dayanand Medical College, Ludhiana, India \\ e. Brain Research Africa Initiative (BRAIN), Yaoundé, Cameroon
}

Correspondences to: Ley Sander,

Box 29, UCL Queen Square Institute of Neurology

33 Queen Square, London

WC1N3BG

Email: I.sander@ucl.ac.uk 


\begin{abstract}
There is a large body of evidence suggesting that parasites could be a major preventable risk factor for epilepsy in low and middle-income countries. We review potentially important substrates for epileptogenesis in parasitic diseases. Taenia solium is the most widely known parasite associated with epilepsy and the risk seems determined mainly by the extent of cortical involvement and the evolution of the primary cortical lesion to gliosis or to a calcified granuloma. For most parasites, however, epileptogenesis is more complex and other favourable host genetic factors and parasite-specific characteristics may be critical. In situations where cortical involvement by the parasite is either absent or minimal, parasiteinduced epileptogenesis through an autoimmune process seems plausible. Further research to identify important markers of epileptogenesis in parasitic diseases will have huge implications for the development of trials to halt or delay onset of epilepsy.
\end{abstract}

Key words: brain; seizures; parasitic diseases

Abbreviations: $\mathrm{BBB}=$ blood-brain barrier; $\mathrm{HS}=$ hippocampal sclerosis; IPI=initial precipitating injury; MMP-9=matrix metalloproteinase-9; MTLE=mesio-temporal lobe epilepsy; PCRpolymerase chain reaction; $\mathrm{RBC}=$ red blood cell; SSA= sub-Sahara Africa; Th=T helper 


\section{Introduction}

The burden of epilepsy seems to be higher in low and middle-income countries where parasitic diseases are also endemic [1]. There is persuasive evidence associating epilepsy with a wide range of parasites [2]. For example, neurocysticercosis is responsible for at least one third of epilepsy in many parts of Asia, Latin America and Sub-Saharan Africa (SSA) [39]. Parasites that have been linked with epilepsy can broadly be classified as microparasites (Plasmodium spp, Toxoplasma spp, and Trypanosoma spp), and macroparasites, which are mostly helminths (Toxocara spp, Onchocerca volvulus, Paragonimus spp, Spirometra mansoni, Schistosoma spp). This distinction is important as the potential mechanistic consideration for epileptogenesis may vary between them; while microparasites most likely cause epilepsy through their capacity, given their small size, to invade the brain directly, macroparasites may depend on the neurotropic properties of their eggs or larvae and/or other indirect mechanisms, to predispose to epilepsy. Much is known about brain involvement in malaria and cysticercosis due to the large populations they impact as well as the unmistakable neurological complications associated with them. Other neurotropic parasites have received less attention, either as they are limited to specific geographic regions (paragonimiasis, schistosomiasis, and trypanosomiasis, sparganosis) or as the evidence supporting brain involvement is lacking (onchocerciasis). Acute brain involvement, however, represents only the tip of the iceberg in parasitic diseases, with respect to the epilepsy risk in the affected individual. A large proportion of those exposed to these parasites remain asymptomatic, yet may still have a significantly increased risk of epilepsy [2]. For example, while latent infection with Toxoplasma spp and Toxocara spp is generally considered to be asymptomatic, ubiquitous exposure to these parasites means that even a modest increase in the risk of epilepsy could significantly contribute to the high burden of epilepsy worldwide. We briefly review parasites which commonly predispose to epileptic seizures and discuss factors likely relevant in the epileptogenic process. Understanding the mechanisms underpinning epileptogenesis in parasitic diseases may be critical in developing interventions for the primary and secondary prevention of epilepsy associated with parasites. 


\section{Parasitic diseases commonly associated with seizures and epilepsy}

\subsection{Malaria}

Over one-third of the world population is exposed to malaria, mainly in Africa [10] where it is one of the main triggers of seizures, especially among children. Seizures are a common occurrence in children with malaria and some of these may be simple febrile seizures. The majority of the seizures are, however, prolonged, have focal characteristics, and occur when the temperature is less than $38^{\circ} \mathrm{C}$, implying that other mechanisms besides fever, probably directly related to the parasite, are involved $[11,12]$. Seizures also occur after recovery from the acute malaria episode, especially after cerebral malaria. In one study, about $10 \%$ of children with cerebral malaria followed up over a substantial period developed epilepsy [13]. Plasmodium falciparum is responsible for most cases of malaria in SSA and is transmitted through bites of the female anopheles mosquito leading to the invasion of red blood cells (RBCs) [10]. Cerebral malaria is the most serious, often fatal presentation, of falciparum malaria, particularly in children in SSA [14]. Parasitic invasion of the cerebral vasculature is the main pathophysiological mechanism and is thought to be responsible for

the acute clinical presentation and neurological sequelae. Typically, the plasma membranes of parasitized RBCs form knobs containing proteins which facilitate their adhesion to the endothelial surface of cerebral vasculature [15]. Through this process, parasitized RBCs progressively become sequestered within the cerebral micro-circulation and form rosettes with uninfected RBCs, thereby compromising blood flow, leading to ischemia and the release of inflammatory cytokines $[16,17]$.

\subsection{Taeniasis/ Cysticercosis}

Neurocysticercosis is the most severe manifestation of infestation by Taenia solium and is believed to be responsible for at least one third of epilepsy cases in endemic regions in Africa, Latin America and Asia $[6,18]$. A recent systematic review estimated that almost two-thirds of epilepsy cases in areas where cysticercosis is endemic is attributable to it; this is even higher for late-onset epilepsy [19]. In the parasite lifecycle, humans become infected by consuming cysts contained in raw or poorly-cooked pork from infected pigs (intermediate hosts); the cysts develop into the adult tapeworm in the intestines (Taeniasis) and eggs passed out in feces contaminate the environment where they are ingested by free-ranging 
pigs. Neurocysticercosis, however, occurs when humans become aberrant intermediate hosts by ingesting eggs which develop into larvae called onchospheres which from the intestines, enter the circulatory system and reach the brain or other tissues where they form cysts. How the parasite traverses the BBB and into the brain parenchyma is poorly understood. Some have suggested that neurotropism may be determined by genetic factors in certain parasite species [20]. Parasites found in the cerebral parenchyma usually evolve through four main stages: vesicular, colloidal, granulo-nodular and granulomatous/calcified stages. The vesicular stage is characterized by a viable cyst containing parasite antigens with immunological properties which enables it to avoid attack by the host immune system [21]. In the colloidal (active) stage the cyst enters a degenerative phase, releasing antigens which trigger an intense inflammatory response [22]. The parasite then progressively degenerates through the granular-nodular stage to either complete involution or a calcified lesion [23]. Seizures can occur at any stage of neurocysticercosis, although the provoking factors are different (see Section 3.1). Neurocysticercosis cysts can also be found in extra-parenchymal structures (racemose variant) and the symptoms depend on the location and number of lesions [24].

\subsection{Onchocerciasis}

Onchocerciasis is caused by microfilariae of Onchocerca volvulus and it is the leading cause of blindness in parts of Africa [25]. There is, however, accruing evidence from case-control studies associating it with epilepsy [26]. Epilepsy prevalence has been shown to increase near to rivers, which are breeding grounds for the vector, the simulium fly $[27,28]$. There is also a positive correlation between hyperendemicity of onchocerciasis and high prevalence of epilepsy [29]. Recent evidence from a cohort study in Cameroon suggests a temporal relationship and etiological gradient between onchocerciasis and epilepsy [30]. Further evidence of a possible causal relationship between onchocerciasis and epilepsy comes from studies implicating onchocerciasis in a childhood epileptic encephalopathy, nodding syndrome. This is characterized by head nodding usually starting around the age of six years followed by cognitive decline, and behavioural problems [31]. Clinical studies of nodding syndrome show that other seizure types are a common feature, sometimes with familial clustering of such cases [31, 32]; this reinforces the argument that nodding syndrome is part 
of a spectrum of seizure disorders in people with epilepsy associated with onchocerciasis. While there seems to be consistent evidence in favour of a causal relationship between onchocerciasis and epilepsy, further studies are needed to confirm this hypothesis, especially given that plausible biological mechanisms of causality remain hypothetical.

Humans are the only definitive host of Onchocerca volvulus and its larvae are introduced by the vector (simulium fly). The larva develops into an adult worm and the female locks itself up in a subcutaneous fibrous capsule and releases microfilariae which mainly migrate to the skin and eye [33]. Microfilariae in the eye provoke neutrophil and eosinophil infiltration and the release of cytokines into the corneal stroma, resulting in corneal opacification and blindness [34]. Wolbachia are rickettsiae transmitted simultaneously with Onchocerca volvulus by the simulium fly which, by promoting larval development and worm fertility, are important in the pathogenesis of onchocerciasis and its complications [35]. There is no strong evidence yet of the presence of microfilariae in the brain, although this does not exclude direct or indirect effects of microfilariae; there seems to be a correlation between positive skin PCR to Onchocerca volvulus and MRI abnormalities in nodding syndrome [36].

\subsection{Toxocariasis}

Toxocariasis is a zoonosis caused by larvae of Toxocara spp, a nematode which inhabits the gut of dogs (Toxocara canis) and cats (Toxocara catis). In humans, ingested embryonated eggs persist in the juvenile larval stages, penetrate through the gut wall and migrate to several body organs. Two broad clinical syndromes of toxocariasis can be distinguished: visceral larva migrans (a systemic inflammatory response to multiple organ involvement); and ocular larva migrans (eye and optic nerve involvement). Cerebral involvement causes a variety of acute neurological syndromes including seizures, [37]. The term "covert toxocariasis" describes chronic infection which is either asymptomatic or associated with only mild and non-specific symptoms. This condition is, however, being increasingly associated with an increased risk of epilepsy in low and high-income countries [38].

\subsection{Toxoplasmosis}

Chronic toxoplasmosis is ubiquitous and has been traditionally considered asymptomatic in immunocompetent people but is increasingly linked with epilepsy [39]. It is caused by Toxoplasma gondii, an obligate intracellular protozoan [40]. Cats are the only known 
definitive hosts and they shed large quantities of oocysts of the parasite in their feces [41]. Humans are intermediates hosts and after cysts are ingested from contaminated food sources, the parasite traverses the intestinal lumen and migrates to the brain with the help of macrophages. Parasites in the neurons undergo proliferation, while those in microglial cells upregulate genes encoding pro-inflammatory and anti-inflammatory cytokines resulting in chronic infection, ensuring survival of the host while maintaining the parasite in a dormant state $[42,43]$.

\subsection{Schistosomiasis}

Schistosomiasis is caused by the trematode, Schistosoma spp, which affects over 200 million people, mostly in Africa [44]. It may be an important risk factor for epilepsy in affected communities. Human disease occurs through contact with fresh water containing freeswimming larvae called cercariae, which penetrate the skin, enter the venous circulation and migrate through the portal circulation to the mesenteric veins or the vesical plexus to produce eggs [44]. The eggs pass into the lumen of the intestines (S. japonicum and $S$. mansoni) and the bladder (S. haematobium) and are shed in faeces or urine [44]. The eggs reach the brain either by embolization through arterio-venous/porto-sytemic shunts or by migration of the parasite through the vertebral venous plexus into the brain parenchyma or meninges to lay eggs in situ in clusters [45]. The inflammatory reaction to the parasite ranges from mild inflammation around scattered ova to severe peri-ovular inflammation, forming giant granulomas [46]. In endemic areas, cerebral invasion can affect over $1 / 4$ of the population, most of whom are asymptomatic [47]. Case reports suggest that seizures can occur several years after exposure to Schistosoma spp [48, 49].

\subsection{Paragonimiasis}

Seizures are the most common presentation of cerebral paragonimiasis [50]. This foodborne disease is caused by Paragonimus spp, a trematode endemic in countries with freshwater bodies where the intermediate hosts live [51]. Paragonimus westermani is the main species responsible for human paragonimiasis. Humans are the definitive host and become infected after consumption of the larvae from raw or poorly cooked crustaceans. Adults live in pairs in the lungs and form cysts which rupture into airways, releasing eggs which are either expelled in sputum or swallowed and passed in feces [52]. The parasites 
reach the brain either by direct migration from the lungs through the jugular foramen or through embolization of its eggs $[53,54]$. Cerebral paragonimiasis is the most common form of extra-pulmonary paragonimiasis and accounts for over $50 \%$ of such cases [54]. It is also a great mimic of cerebrovascular disorders [55-57].

\subsection{Sparganosis}

Sparganosis was associated with epilepsy in one Korean case-control study, reporting an odds ratio of 1.3 [58]. It is caused by sparganum, the plerocercoid larva of the cestode, Spirometra mansoni. This parasite is only seen in Asia, mostly limited to China, Japan, Korea and Taiwan [59]. Cats and dogs are the definitive host and harbor adult worms which shed eggs that are passed out in feces and evolve through several larval stages within intermediate hosts in fresh water. Human disease results either from drinking water contaminated with copepods or from eating poorly cooked intermediate hosts which contain sparganum. Cerebral involvement is usually chronic and presents as recurrent headaches or epileptic seizures although it may mimic a brain tumour [59].

\subsection{Human African Trypanosomiasis}

Seizures are one of the main symptoms in the chronic stage of Human African Trypanosomiasis (HAT). This is limited to rural communities in sub-Saharan Africa where its vector (tsetse fly) is found, although sustained control efforts by the WHO have led to nearelimination in most countries [60]. It is caused by the protozoa Trypanosoma, and Trypanosoma brucei gambiense is responsible for almost all cases. It is transmitted to humans by bites from infected tsetse flies which acquire the infection by biting infected humans or animals. Cerebral involvement occurs in chronic infestation when the parasites cross the blood brain barrier to the CNS.

\section{Mechanistic considerations for epileptogenesis in parasitic diseases}

\subsection{Distinguishing between acute symptomatic seizures and remote symptomatic seizures}

It is important to distinguish between acute and remote symptomatic seizures when discussing seizures related to parasitic diseases [61]. Acute symptomatic seizures are the result of temporary disturbances in neuronal function, mainly due to inflammation in the 
cerebral cortex directed against the parasite; they often subside when the inflammation stops [62]. Conversely, remote symptomatic seizures are usually recurrent and probably result from long-term structural and functional changes in the brain parenchymal networks causing hyper-excitation and synchronization of neurons (Table 1). Neurophysiological and imaging studies, when available, are helpful in diagnosing acute symptomatic seizures; focal EEG abnormalities usually correlate with lesion location and "activity" on MRI [63].

Epileptogenesis is the development and extension of tissues capable of generating spontaneous epileptic seizures, including the development of epilepsy and progression after the condition is established [64]. Brain invasion by the parasite contributes to this process by causing several structural changes in the cerebral cortex: cerebro-vascular lesions; calcification; gliosis; and hippocampal sclerosis (HS). These cerebral lesions alone may not suffice for the development of epilepsy in an individual. For example, they do not explain epileptogenesis in cases where brain involvement is either limited or absent. Other host and parasite- specific factors, may thus be necessary for the development and progression of enhanced excitation and synchronization of cortical networks. Below, we present factors that may be important triggers or catalysts of epileptogenesis (Figures 1-3).

\subsection{Epileptogenic Cortical insults}

\section{Cerebrovascular lesions}

Vascular insults involving the cerebral cortex can lead to epilepsy. Cerebrovascular disorders engender unprovoked seizures due to the deposition of products of blood decomposition (in haemorrhagic stroke), neuronal cell loss and re-organization of neuronal circuitry favouring synchronisation in the cerebral cortex [65]. Cerebral paragonimiasis and schistosomiasis affect large vessels and may mimic cerebrovascular disorders in causing haemorrhage and vascular obstruction $[66,67]$. Stroke resulting from occlusion of the large arteries at the base of the brain, as well as of the deeper penetrating arteries, is a recognized manifestation of neurocysticercosis, particularly the meningeal-racemose variety [24]. In cerebral malaria, central parasitaemia and raised excitotoxic amino acids cause hypoxicischaemic events that may be responsible for structural brain changes [68-70]. MRI scans of survivors of cerebral malaria 6-24 months after onset of neurological sequelae show several types of lesions of probable epileptogenic potential: periventricular T2 signal changes, 
atrophy, and focal cortical defects [71]. Sonographic abnormalities associated with lateralization deficits are common in children with cerebral malaria who develop neurological sequelae, and this suggests some structural or perfusion perturbations as the cause of the deficit [72]. Occasionally, the vasculopathy and perivascular inflammation and oedema lead to demyelination and the formation of a granuloma (Durk's Granuloma) [73], which could all lead to recurrent seizures.

\section{Calcified lesions}

Evolution of a parasitic brain lesion to a calcific granuloma is most commonly encountered in cerebral paragonimiasis and neurocysticercosis but can occur in any brain invasion where granulomatous inflammatory lesions are formed. In neurocysticercosis, the evolution of the granuloma to a calcified lesion seems to be a strong predictor of seizure recurrence [74]. Perilesional oedema around the calcified lesions seems to be critical in determining their epileptogenic potential [75-77]. The oedema results from intermittent exacerbations in inflammation, possibly driven by periodic release of antigenic remnants of the parasite in the calcified lesion [78]. On pathological examination, perilesional oedema typically consists of mononuclear infiltrates in the capsule around the calcified cyst extending to the adjacent brain, which also shows signs of marked gliosis, astrocytosis and perivascular infiltrates [79]. Even in situations where seizures occur in the absence of obvious perilesional oedema, it has been suggested that undetectable low levels of inflammation may still be sufficient to generate seizures or facilitate kindling of the hippocampus [80]. Apart from perilesional oedema, calcified cysts could also provoke seizures through the toxic effect of calcium itself on the surrounding cortex [81].

\section{Gliosis}

Gliosis may occur after recovery from the acute brain inflammation associated with parasitic infection. Gliosis is most significant in parasitic diseases such as neurocysticercosis, paragonimiasis, schistosomiasis and sparganosis where brain involvement is associated with significant inflammation around the affected cortical tissue. In neurocysticercosis, gliosis around the cyst is known to predict seizure recurrence and refractory seizures $[82,83]$. This is supported by histological evidence of gliosis surrounding lesions after resection in people with intractable epilepsy [79]. One prospective study reported that people with neurocysticercosis with perilesional gliosis had more contralateral abnormal motor 
phenomena, corresponding with EEG abnormalities than people with neurocysticercosis without perilesional gliosis; these subtle "inter-ictal" symptoms could be epileptic phenomena associated with the perilesional gliosis [84].

\section{Hippocampal sclerosis}

Due to their increased excitability, mesio-temporal structures have a higher tendency than other parts of the brain to be involved in epileptic seizures, even when the focal lesion is located elsewhere in the cerebral cortex [65]. Consequently, by their invasion of mesiotemporal structures or other parts of the cortex with networks linked to the hippocampus, some parasites increase the risk of hippocampal sclerosis (HS). Cerebral malaria has been shown to lead to hippocampal damage in children [85]. Experiments in mice show that cerebral malaria interferes with hippocampal neurogenesis and increases hippocampal cell death [86]. Some studies suggest a link between neurocysticercosis and mesio-temporal lobe epilepsy with HS (MTLE-HS) [87-89]. There also seems to be a correlation between the side of the HS and that of the calcified cysts [88, 90-92]. Neurocysticercosis may cause MTLE by provoking the initial precipitating injury (IPI) that leads to HS, as MTLE and neurocysticercosis occur more commonly together among older people and those lacking a classical IPI $[88,90]$. The IPI could result from the perilesional oedema around a calcified lesion located in the temporal lobe, mediated by increased expression of matrix metalloproteinase-9 (MMP-9) [93]. In animal experiments, there is preferential expression of MMP-9 in the dentate gyrus of the hippocampus following stimulation with a glutamate receptor (kainate), suggesting that it may be involved in activity-dependent re-modelling of dendritic architecture with possible effects on synaptic physiology [94].

\section{Kindling effects of febrile seizures and acute symptomatic seizures}

In acute cerebral insult, the occurrence of acute symptomatic seizures increase the risk of remote symptomatic seizures [65]. Malaria-associated seizures are mostly of a complex phenotype and, together with febrile seizures, are associated with an increased risk of developing epilepsy after recovery $[13,95]$. In neurocysticercosis, the inflammatory cascade around the degenerative cyst, especially in the colloidal stage, is the main trigger of acute symptomatic seizures [96]. These seizures are often complex, occurring in clusters and with status epilepticus being common [97]; they probably predispose to epilepsy by engendering 
the development of secondary epileptogenic lesions $[98,99]$. Secondary epileptogenic lesion formation is thought to result from downhill morphological changes, mostly along the corpus callosum, from the propagation of continuous epileptiform discharges [65].

\section{Alteration of neuronal function}

Toxoplasma gondii affects neuronal function though a variety of ways (Table 1): direct neuronal damage; disturbance in serotonin metabolism leading to tryptophan depletion; and increased production of substances such as quinolinic acid [100]. Quinolinic acid is an NMDA receptor agonist which can provoke seizures and, together with similar substances, can also cause neuronal death by facilitating the production of reactive oxygen species [100]. These substances, through their excitotoxic effects on neurons may alter the balance between excitation and inhibition in the cortex, predisposing to epilepsy.

\subsection{Immunological considerations}

In situations where cortical involvement by the parasite is either absent or minimal, autoimmune phenomena could be triggers or catalysts of epileptogenesis. Similarities have been shown between E1 antigens of Onchocerca volvulus and some neuronal antigens [101] raising the possibility of an autoimmune mechanism (similar to that which occurs in the skin manifestation of the disease) as cause of epilepsy in onchocerciasis. The autoimmune hypothesis has been reinforced by evidence from a recent study of nodding syndrome showing that antibodies to leiomodin-1, a protein that is cross-reactive with Onchocerca volvulus antigens, are more common in the sera and the CSF of people with nodding syndrome than in healthy subjects. The researchers also demonstrated that anti-leiomodin1 antibodies are neurotoxic and that leimodin-1 is preferentially expressed in parts of the mouse brain similar to those of people with nodding syndrome [102].

Immunity to severe forms of parasitic infestations or lack thereof, could also determine the risk of epilepsy. Immunological response to malaria is complex and although a substantial reduction of the transmission of plasmodium through vector control probably reduces the incidence of malaria and hence the risk of epilepsy, this effect is diluted by the increased risk of cerebral malaria in immunologically naïve children at an older age [103]. Some have 
shown that low levels of IgM and IgG against certain Plasmodium falciparum antigens may predispose to severe malaria and that an imbalanced pro-inflammatory cytokine response may exacerbate the severity of infection and perhaps the risk of epilepsy [104]. Acquired immunity due to constant exposure to onchospheres of Taenia solium seems to be important in mitigating the severity of neurocysticercosis and the risk of epilepsy [105].

\subsection{Genetic factors}

In general, genetic predisposition might occur at four different levels: genetic predisposition to parasitic disease; genetic factors that determine the nature of the inflammatory response mounted in the brain against the parasite; genetic predisposition to acute seizures during infection; genetic susceptibility to unprovoked seizures. A pre-existing genetic predisposition to epilepsy which was previously sub-clinical may become clinically evident because of the development of a potentially epileptogenic parasitic brain lesion. Epilepsy susceptibility genes may be present due to sporadic genetic mutations, or inherited from parents, who themselves may not be clinically affected by epilepsy. In cerebral malaria, a family history of epilepsy is significantly associated with an increased risk of epilepsy and an adverse neurological outcome $[106,107]$. One African study showed that children admitted with falciparum malaria may have a genetic predisposition to acute seizures [12]; it is not clear how this impacts on the risk of epilepsy. In a large genetic study among Gambian children, it was concluded that polymorphisms for certain cytokine genes such as homozygotes of the TNF2 allele, implicated in the pathogenesis of cerebral malaria, may be associated with a seven-fold increase in the risk of death and neurological sequelae after cerebral malaria [108]. In neurocysticercosis, genetic factors in certain hosts play an important role in determining the severity of the inflammatory response. There is evidence showing that TLR4 genetic polymorphism is a risk factor for the development of epilepsy in people with NCC, by contributing to alteration of the Th1/Th2 axis, favouring inflammation [109]. In one study, significantly higher MMP-9 gene polymorphism with differential upregulation of MMP-9 was observed in people with symptomatic NCC compared with those with no symptoms [93]. From pathological studies of cerebral malaria in humans and animals, it can be speculated that an imbalance between factors promoting brain injury and neuroprotective factors such as nuclear factor kappa-B and neuroglobin contributes to the epilepsy risk [110, 111]. 


\subsection{Favourable parasite-specific factors}

Some parasites may accelerate the epileptogenic process by predisposing affected individuals to other risk factors of epilepsy. Studies show that toxoplasmosis can lead to manipulation of behavior and reduced psychomotor performance through its effect on dopamine and testosterone [112]. People with chronic toxoplasmosis are at increased risk of road traffic accidents [113-115] which could in turn increase the risk of post-traumatic epilepsy. Behavioral manipulation by toxoplasma could also predispose to epilepsy by promoting exposure to other parasites which cause epilepsy. People with toxoplasmosis have twice the odds of being co-infected with Toxocara spp, another risk factor for epilepsy [116]. There is also some suggestion that multiple parasite exposure, especially if including toxoplasmosis or onchocerciasis, could further increase the epilepsy risk beyond the additive risk of the individual parasites [117].

Certain parasite species, by their predilection for neural tropism, confer a higher epileptogenic risk than those with less neural tropism. In neurocysticercosis, it has been postulated that differences in neural tropism, conferred by the genetic differences between species of Taenia solium, are partially responsible for variations in the risk of neurocysticercosis and epilepsy observed between similar pig rearing communities [20]. This genetic variation appears to be promoted by concomitant immunity exhibited by pigs to cysticerci from different geographical regions [118].

Through their endosymbiotic relationship with certain parasites, some pathogens could either provoke an epileptogenic lesion in the brain or facilitate the progression of an epileptogenic lesion initiated by the parasite itself. Onchocerciasis could cause epilepsy indirectly through a hypothetical indirect mechanism involving Wolbachia, which is cotransmitted with Onchocerca microfilariae and is known to play a role in the pathogenesis of river blindness. Chronic filariasis has a modulatory effect on the immune system [119]. It is possible that the death of microfilariae releases Wolbachia antigens, triggering an inflammatory response that results in breakdown of the BBB, enabling access of either microfilaria or Wolbachia, or both, into the brain. Epileptic seizures could then result from a sustained inflammatory response leading to neuronal loss and gliosis as a result of repeated exposure to Wolbachia. If this were the case, one would expect Wolbachia or inflammatory 
markers in the CSF to reflect the ongoing inflammatory process. These have not been shown so far [120]. While there is some suggestion that good therapeutic coverage with Ivermectin may have resulted in a reduction in the incidence of epilepsy in some endemic areas [121], it is important that this is further investigated using robust prospective studies. It would be interesting to investigate whether Ivermectin has any effect on Wolbachia and whether anti-bacterial treatment targeting Wolbachia would have any effect on epilepsy incidence, providing indirect evidence of a Wolbachia role in the development of epilepsy.

\section{Conclusion}

Taenia solium is the most widely known parasite associated with epilepsy and epilepsy risk seems determined mainly by the extent of cortical involvement and the evolution of the primary cortical lesion to gliosis or to a calcified granuloma. For most parasites, however, epileptogenesis is more complex and other favourable host genetic factors and parasitespecific characteristics may be critical. In situations where direct cortical involvement by the parasite is either absent or minimal, parasite-induced epileptogenesis through an autoimmune process seems plausible. Further research to identify important markers of epileptogenesis in parasitic diseases will have huge implications for the development of trials to halt or delay onset of epilepsy in endemic areas. 


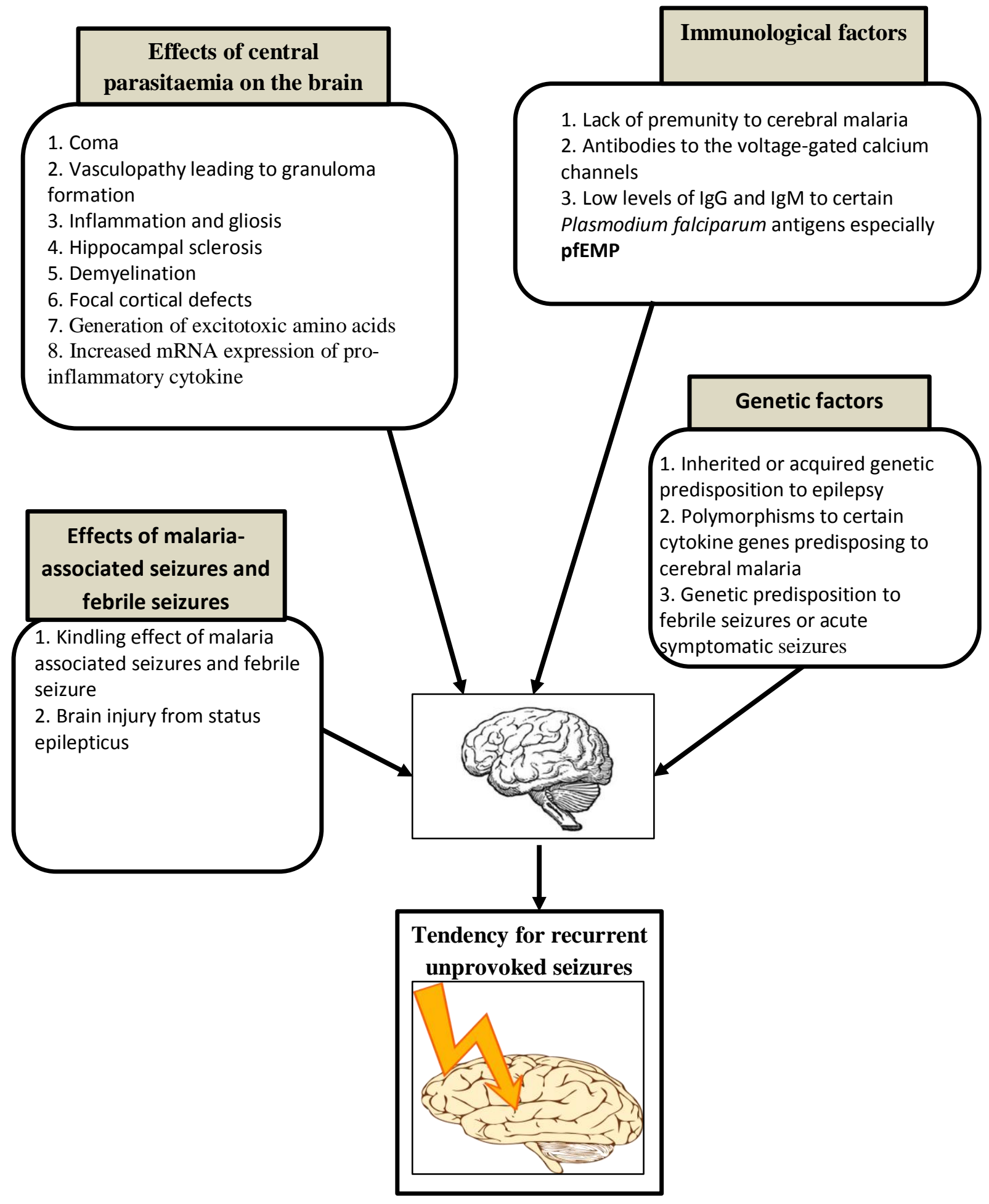

Figure 1: Possible epileptogenic substrates of malaria 


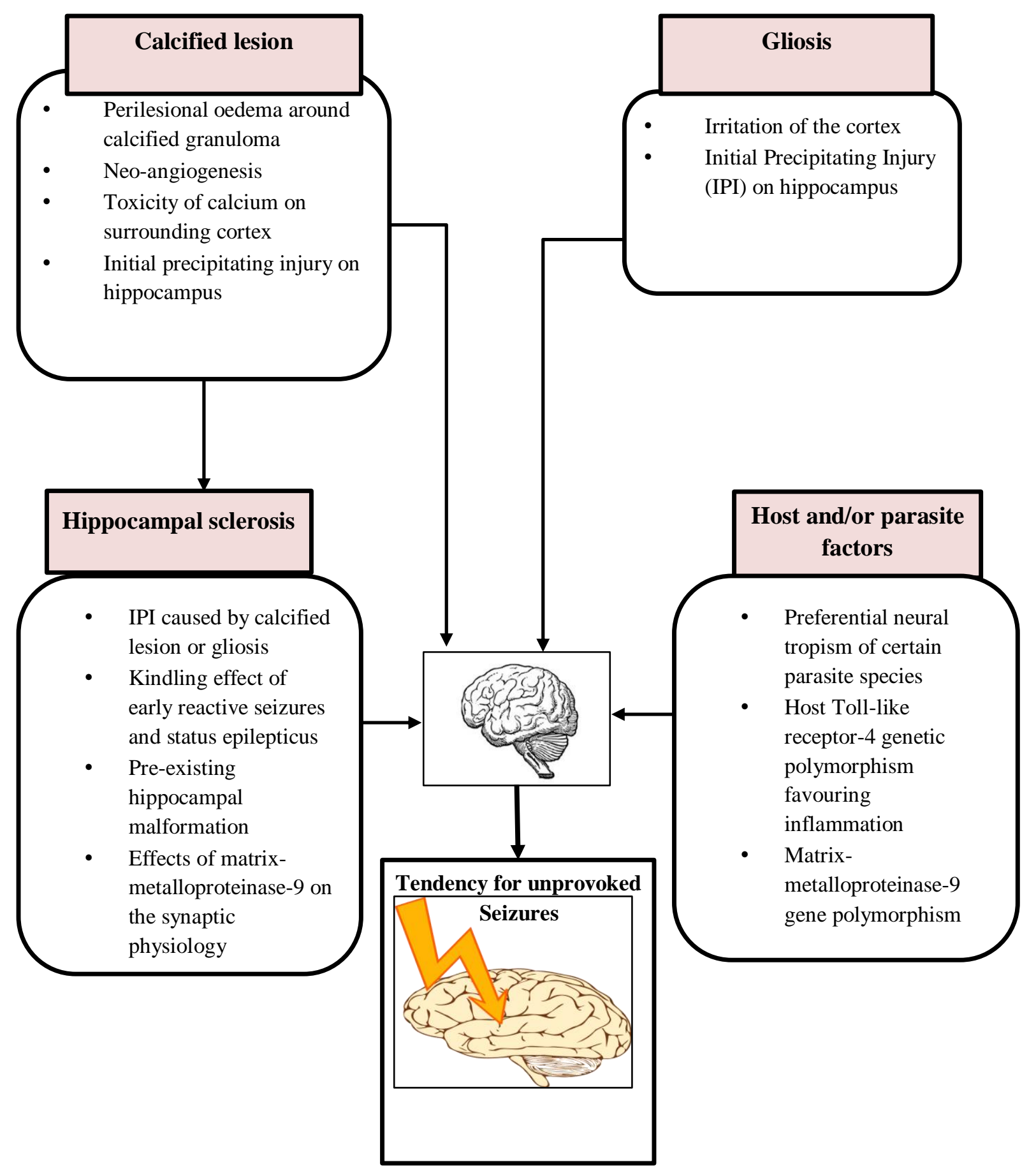

Figure 2: Possible epileptogenic substrates in neurocysticercosis

We need to check that all the words in the boxes are visible. For example, I had to change things to see the word 'physiology' in the HS box 


\section{Autoimmune phenomena}

1. Similarities between antigens of $O$.

volvulus and ankyrin-related proteins in parts

of the neuronal cell

2. Antibodies to leiomodin-1, a protein cros reacting with $O$. volvulus and expressed i human neurons,

\section{Invasion of brain by microfilariae} and/or Wolbachia

1. Findings of microfilariae in blood urine and cerebrospinal fluid

2. Microfilariae load correlates positively with risk of epilepsy

3. Wolbachia burden associated with disease severity

\section{(1)}

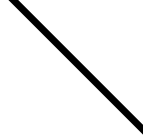
Host predisposition

1. Chronic ill-health due to onchocerciasis

2. Preexisting factors predisposing to epilepsy

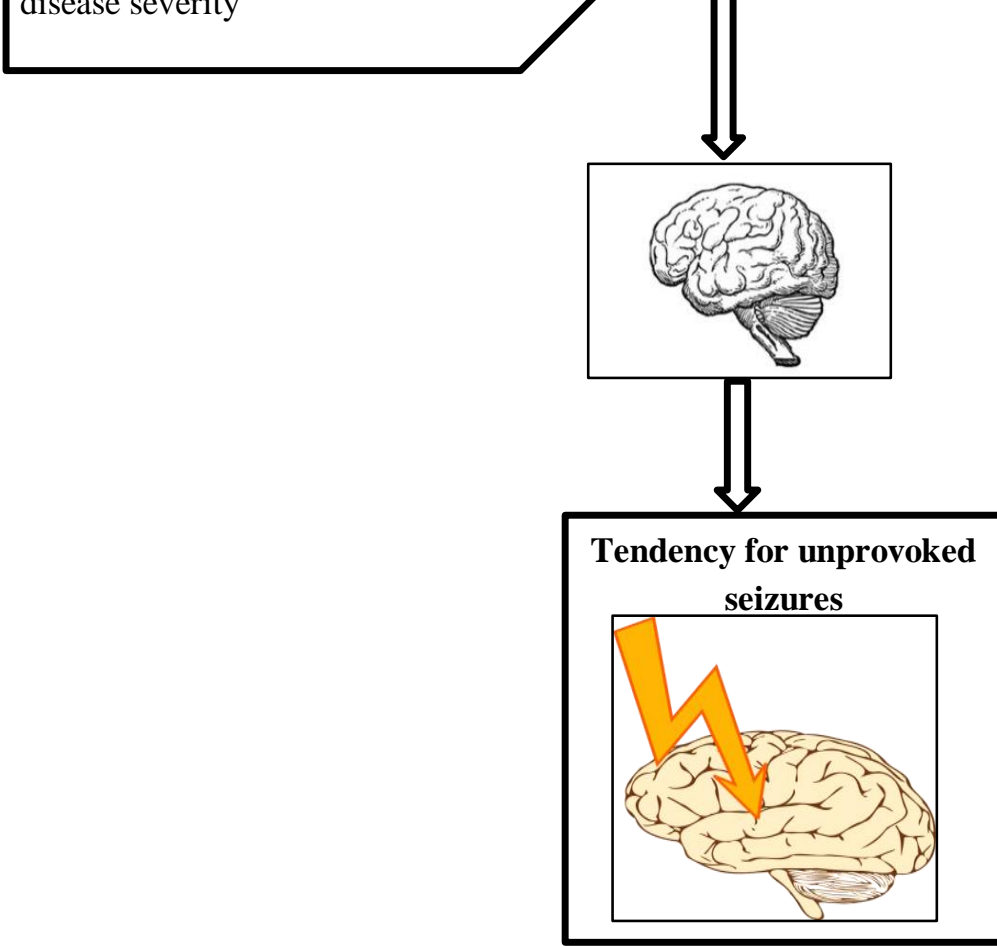

Figure 3: Possible epileptogenic pathways of onchocerciasis 
Table 1. Causes of early reactive and late seizures in parasitic diseases

\begin{tabular}{|c|c|c|c|}
\hline Parasite & Disease & $\begin{array}{l}\text { Cause of acute symptomatic } \\
\text { seizures }\end{array}$ & $\begin{array}{l}\text { Probable causes of remote symptomatic } \\
\text { seizures }\end{array}$ \\
\hline $\begin{array}{l}\text { Plasmodium } \\
\text { falciparum } \\
\text { (microparasite) }\end{array}$ & Malaria & $\begin{array}{l}\text { Hypoxic-ischaemic effects of } \\
\text { parasitized RBCs on cerebral } \\
\text { micro-vasculature; fever; } \\
\text { anaemia; electrolyte } \\
\text { disturbance; hypoglycaemia }\end{array}$ & $\begin{array}{l}\text { 1. Parenchymal brain damage due to effects } \\
\text { of coma and central parasitaemia } \\
\text { 2. Kindling effect of malaria-associated } \\
\text { seizures, febrile seizures and status } \\
\text { epilepticus } \\
\text { 3. Demyelination, gliosis and granuloma }\end{array}$ \\
\hline $\begin{array}{l}\text { Taenia solium } \\
\text { (macroparasite) }\end{array}$ & Neurocysticercosis & $\begin{array}{l}\text { Larval antigens cause release } \\
\text { of inflammatory cytokines, } \\
\text { breakdown of the BBB and } \\
\text { neo-angiogenesis }\end{array}$ & $\begin{array}{l}\text { 1. Evolution of cyst to calcified granuloma } \\
\text { with accompanying peri-lesional oedema } \\
\text { 2. Hippocampal sclerosis due to gliosis } \\
\text { 3. Kindling effect of acute symptomatic } \\
\text { seizures and chronic low-level inflammation } \\
\text { in the calcified granuloma }\end{array}$ \\
\hline $\begin{array}{l}\text { Onchocerca volvulus } \\
\text { (macroparasite) }\end{array}$ & Onchocerciasis & $\begin{array}{l}\text { No known acute neurological } \\
\text { features }\end{array}$ & $\begin{array}{l}\text { 1. Auto-immune phenomena } \\
\text { 2. Brain invasion by microfilariae or } \\
\text { Wolbachia }\end{array}$ \\
\hline $\begin{array}{l}\text { Toxocara spp } \\
\text { (macroparasite) }\end{array}$ & Toxocariasis & $\begin{array}{l}\text { Very little inflammation in the } \\
\text { acute phase so seizures rare }\end{array}$ & $\begin{array}{l}\text { 1. Chronic infestation increases } \\
\text { neurotropism of the parasite and risk of } \\
\text { brain damage } \\
\text { 2. Astrogliosis } \\
\text { 3. Increased expression of pro-inflammatory } \\
\text { cytokines } \\
\text { 4. Disturbances in neurotransmitter profile, } \\
\text { favouring excitation }\end{array}$ \\
\hline $\begin{array}{l}\text { Toxoplasma gondii } \\
\text { (microparasite) }\end{array}$ & Toxoplasmosis & $\begin{array}{l}\text { Immuno-compromised hosts: } \\
\text { multiple focal parenchymatous } \\
\text { inflammatory lesions and } \\
\text { encephalopathy } \\
\text { Immunocompetent hosts: little } \\
\text { or no inflammation }\end{array}$ & $\begin{array}{l}\text { 1. Neuronal damage by the parasite } \\
\text { 2. Production of excitotoxic substances and } \\
\text { reactive oxygen species } \\
\text { 3. Gene upregulation, manipulation of } \\
\text { behavior and reduced psychomotor } \\
\text { performance, exposing to other acquired } \\
\text { risk factors of epilepsy such as head injury }\end{array}$ \\
\hline $\begin{array}{l}\text { Schistosoma spp } \\
\text { (macroparasite) }\end{array}$ & Schistosomiasis & $\begin{array}{l}\text { Peri-ovular inflammation and } \\
\text { formation of granuloma, } \\
\text { Cerebral hemorrhage }\end{array}$ & $\begin{array}{l}\text { 1. Gliosis from granulomata in the acute } \\
\text { infection or from asymptomatic ova } \\
\text { deposition } \\
\text { 2. Cortical irritation caused by blood } \\
\text { products from cerebral hemorrhage }\end{array}$ \\
\hline $\begin{array}{l}\text { Paragonimus } \\
\text { westermani } \\
\text { (macroparasite) }\end{array}$ & Paragonimiasis & $\begin{array}{l}\text { Inflammation, arteritis, } \\
\text { hemorrhage and mass effect }\end{array}$ & $\begin{array}{l}\text { 1. Calcified lesion } \\
\text { 2. Gliosis }\end{array}$ \\
\hline $\begin{array}{l}\text { Spirometra mansoni } \\
\text { (macroparasite) }\end{array}$ & Sparganosis & Granulomatous reaction & Gliosis \\
\hline $\begin{array}{l}\text { Trypanasoma brucei } \\
\text { gambiense } \\
\text { (microparasite) }\end{array}$ & $\begin{array}{l}\text { Human African } \\
\text { Trypanosomiasis }\end{array}$ & & Neuronal loss \\
\hline
\end{tabular}

There are some UK English spellings in this table and throughout the manuscript. I guess the editors

will remove them - and does it matter if they don't? 


\section{Acknowledgements}

This work was carried out at NIHR University College London Hospitals Biomedical Research Centre, which receives a proportion of funding from the UK Department of Health's Research Centers funding scheme. JWS receives research support from the Dr Marvin Weil Epilepsy Research Fund and from the UK Epilepsy Society. SAA is a Commonwealth scholar and is funded by the UK Department of International Development.

\section{References}

[1] Fiest KM, Sauro KM, Wiebe S, Patten SB, Kwon CS, Dykeman J, Pringsheim T, Lorenzetti DL, Jette N. Prevalence and incidence of epilepsy: A systematic review and metaanalysis of international studies. Neurology 2017;88: 296-303.

[2] Ba-Diop A, Marin B, Druet-Cabanac M, Ngoungou EB, Newton CR, Preux P-M. Epidemiology, causes, and treatment of epilepsy in sub-Saharan Africa. Lancet Neurol 2014;13: 1029-1044.

[3] Mwape KE, Blocher J, Wiefek J, Schmidt K, Dorny P, Praet N, Chiluba C, Schmidt H, Phiri IK, Winkler AS, Gabriël S. Prevalence of neurocysticercosis in people with epilepsy in the Eastern province of Zambia. PLoS Negl Trop Dis 2015;9.

[4] Winkler AS, Blocher J, Auer H, Gotwald T, Matuja W, Schmutzhard E. Epilepsy and neurocysticercosis in rural Tanzania - An imaging study. Epilepsia 2009;50: 987-993.

[5] Nsengiyumva G, Druet-Cabanac M, Ramanankandrasana B, Bouteille B, Nsizabira L, Preux PM. Cysticercosis as a major risk factor for epilepsy in Burundi, east Africa. Epilepsia 2003;44: 950-5.

[6] Millogo A, Nitiéma P, Carabin H, Boncoeur-Martel MP, Rajshekhar V, Tarnagda Z, Praet N, Dorny P, Cowan L, Ganaba R, Hounton S, Preux PM, Cissé R. Prevalence of neurocysticercosis among people with epilepsy in rural areas of Burkina Faso. Epilepsia 2012;53: 2194-2202.

[7] Raina SK, Razdan S, Pandita KK, Sharma R, Gupta VP, Razdan S. Active epilepsy as indicator of neurocysticercosis in rural northwest India. Epilepsy Res Treat 2012;2012: 802747.

[8] Cruz ME, Schantz PM, Cruz I, Espinosa P, Preux PM, Cruz A, Benitez W, Tsang VC, Fermoso J, Dumas M. Epilepsy and neurocysticercosis in an Andean community. Int J Epidemiol 1999;28: 799-803.

[9] Rajshekhar V, Raghava MV, Prabhakaran V, Oommen A, Muliyil J. Active epilepsy as an index of burden of neurocysticercosis in Vellore district, India. Neurology 2006;67: 2135-9.

[10] WHO. 2015. Malaria [Online]. Available: http://www.who.int/topics/malaria/en/ [Accessed 30 Mrach 2016]. 
[11] Waruiru CM, Newton CR, Forster D, New L, Winstanley P, Mwangi I, Marsh V, Winstanley M, Snow RW, Marsh K. Epileptic seizures and malaria in Kenyan children. Trans R Soc Trop Med Hyg 1996;90: 152-5.

[12] Kariuki SM, Rockett K, Clark TG, Reyburn H, Agbenyega T, Taylor TE, Birbeck GL, Williams TN, Newton CR. The genetic risk of acute seizures in African children with falciparum malaria. Epilepsia 2013;54: 990-1001.

[13] Birbeck GL, Molyneux ME, Kaplan PW, Seydel KB, Chimalizeni YF, Kawaza K, Taylor TE. Blantyre Malaria Project Epilepsy Study (BMPES) of neurological outcomes in retinopathy-positive paediatric cerebral malaria survivors: A prospective cohort study. Lancet Neurol 2010;9: 1173-1181.

[14] Oluwayemi IO, Brown BJ, Oyedeji OA, Oluwayemi MA. Neurological sequelae in survivors of cerebral malaria. PAMJ 2013;15.

[15] Turner GD, Morrison H, Jones M, Davis TM, Looareesuwan S, Buley ID, Gatter KC, Newbold CI, Pukritayakamee S, Nagachinta B, et al. An immunohistochemical study of the pathology of fatal malaria. Evidence for widespread endothelial activation and a potential role for intercellular adhesion molecule-1 in cerebral sequestration. Am J Pathol 1994;145: 1057-69.

[16] Doumbo OK, Thera MA, Kone AK, Raza A, Tempest LJ, Lyke KE, Plowe CV, Rowe JA. High levels of Plasmodium falciparum rosetting in all clinical forms of severe malaria in African children. Am J Trop Med Hyg 2009;81: 987-993.

[17] Tripathi AK, Sha W, Shulaev V, Stins MF, Sullivan DJ, Jr. Plasmodium falciparuminfected erythrocytes induce NF-kappaB regulated inflammatory pathways in human cerebral endothelium. Blood 2009;114: 4243-52.

[18] Medina MT, Aguilar-Estrada RL, Alvarez A, Duron RM, Martinez L, Dubon S, Estrada AL, Zuniga C, Cartagena D, Thompson A, Ramirez E, Banegas L, Osorio JR, Delgado-Escueta AV, Collins JS, Holden KR. Reduction in rate of epilepsy from neurocysticercosis by community interventions: the Salama, Honduras study. Epilepsia 2011;52: 1177-85.

[19] Debacq G, Moyano LM, Garcia HH, Boumediene F, Marin B, Ngoungou EB, Preux PM. Systematic review and meta-analysis estimating association of cysticercosis and neurocysticercosis with epilepsy. PLoS Negl Trop Dis 2017;11: e0005153.

[20] Vega R, Pinero D, Ramanankandrasana B, Dumas M, Bouteille B, Fleury A, Sciutto E, Larralde C, Fragoso G. Population genetic structure of Taenia solium from Madagascar and Mexico: implications for clinical profile diversity and immunological technology. Int $\mathbf{J}$ Parasitol 2003;33: 1479-85.

[21] Amit P, Prasad KN, Kumar GR, Shweta T, Sanjeev J, Kumar PV, Mukesh T. Immune response to different fractions of Taenia solium cyst fluid antigens in patients with neurocysticercosis. Exp Parasitol 2011;127: 687-92.

[22] Verma A, Prasad KN, Cheekatla SS, Nyati KK, Paliwal VK, Gupta RK. Immune response in symptomatic and asymptomatic neurocysticercosis. Med Microbiol Immunol 2011;200: 255-61.

[23] Lerner A, Shiroishi MS, Zee CS, Law M, Go JL. Imaging of neurocysticercosis. Neuroimaging Clin N Am 2012;22: 659-76.

[24] Mahale RR, Mehta A, Rangasetty S. Extraparenchymal (Racemose)

Neurocysticercosis and Its Multitude Manifestations: A Comprehensive Review. J Clin Neurol 2015;11: 203-11.

[25] Coffeng LE, Stolk WA, Zoure HG, Veerman JL, Agblewonu KB, Murdoch ME, Noma M, Fobi G, Richardus JH, Bundy DA, Habbema D, de Vlas SJ, Amazigo UV. African 
programme for onchocerciasis control 1995-2015: updated health impact estimates based on new disability weights. PLoS Negl Trop Dis 2014;8: e2759.

[26] Kaiser C, Pion SDS, Boussinesq M. Case-control Studies on the Relationship between Onchocerciasis and Epilepsy: Systematic Review and Meta-analysis. PLoS Negl Trop Dis 2013;7.

[27] Boussinesq M, Pion SD, Demanga N, Kamgno J. Relationship between onchocerciasis and epilepsy: a matched case-control study in the Mbam Valley, Republic of Cameroon. Trans R Soc Trop Med Hyg 2002;96: 537-41.

[28] Colebunders R, Tepage F, Rood E, Mandro M, Abatih EN, Musinya G, Mambandu G, Kabeya J, Komba M, Levick B, Mokili JL, Laudisoit A. Prevalence of River Epilepsy in the Orientale Province in the Democratic Republic of the Congo. PLoS Negl Trop Dis 2016;10: e0004478.

[29] Pion SDS, Kalser C, Boutros-Toni F, Cournil A, Taylor MM, Meredith SEO, Stufe A, Bertocchi I, Kipp W, Preux PM, Boussinesq M. Epilepsy in onchocerciasis endemic areas: Systematic review and meta-analysis of population-based surveys. PLoS Negl Trop Dis $2009 ; 3$.

[30] Chesnais CB, Nana-Djeunga HC, Njamnshi AK, Lenou-Nanga CG, Boulle C, Bissek AZ, Kamgno J, Colebunders R, Boussinesq M. The temporal relationship between onchocerciasis and epilepsy: a population-based cohort study. Lancet Infect Dis 2018.

[31] Idro R, Opoka RO, Aanyu HT, Kakooza-Mwesige A, Piloya-Were T, Namusoke H, Musoke SB, Nalugya J, Bangirana P, Mwaka AD, White S, Chong K, Atai-Omoruto AD, Mworozi E, Nankunda J, Kiguli S, Aceng JR, Tumwine JK. Nodding syndrome in Ugandan children--clinical features, brain imaging and complications: a case series. BMJ Open 2013;3. [32] Colebunders R, Abd-Elfarag G, Carter JY, Olore PC, Puok K, Menon S, Fodjo Siewe JN, Bhattacharyya S, Ojok M, Lako R, Logora MY. Clinical characteristics of onchocerciasis-associated epilepsy in villages in Maridi County, Republic of South Sudan. Seizure 2018;62: 108-115.

[33] Burnham G. Onchocerciasis. Lancet 1998;351: 1341-6.

[34] Gillette-Ferguson I, Daehnel K, Hise AG, Sun Y, Carlson E, Diaconu E, McGarry HF, Taylor MJ, Pearlman E. Toll-like receptor 2 regulates CXC chemokine production and neutrophil recruitment to the cornea in Onchocerca volvulus/Wolbachia-induced keratitis. Infect Immun 2007;75: 5908-15.

[35] Hise AG, Gillette-Ferguson I, Pearlman E. Immunopathogenesis of Onchocerca volvulus keratitis (river blindness): a novel role for TLR4 and endosymbiotic Wolbachia bacteria. J Endotoxin Res 2003;9: 390-4.

[36] Winkler AS, Friedrich K, Velicheti S, Dharsee J, König R, Nassri A, Meindl M, Kidunda A, Müller TH, Jilek-Aall L, Matuja W, Gotwald T, Schmutzhard E. MRI findings in people with epilepsy and nodding syndrome in an area endemic for onchocerciasis: An observational study. Afr Health Sci 2013;13: 529-540.

[37] Despommier D. Toxocariasis: clinical aspects, epidemiology, medical ecology, and molecular aspects. Clin Microbiol Rev 2003;16: 265-72.

[38] Quattrocchi G, Nicoletti A, Marin B, Bruno E, Druet-Cabanac M, Preux PM.

Toxocariasis and epilepsy: systematic review and meta-analysis. PLoS Negl Trop Dis 2012;6: e1775.

[39] Ngoungou EB, Bhalla D, Nzoghe A, Darde M-L, Preux P-M. Toxoplasmosis and Epilepsy - Systematic Review and Meta Analysis. Plos Negl Trop Dis 2015;9.

[40] Lafferty KD. Can the common brain parasite, Toxoplasma gondii, influence human culture? Proc Biol Sci 2006;273: 2749-55.

[41] Lyons RE, McLeod R, Roberts CW. Toxoplasma gondii tachyzoite-bradyzoite interconversion. Trends Parasitol 2002;18: 198-201. 
[42] Suzuki Y. Immunopathogenesis of cerebral toxoplasmosis. J Infect Dis 2002;186 Suppl 2: S234-40.

[43] Suzuki Y. Host resistance in the brain against Toxoplasma gondii. J Infect Dis 2002;185 Suppl 1: S58-65.

[44] Ross AG, Bartley PB, Sleigh AC, Olds GR, Li Y, Williams GM, McManus DP. Schistosomiasis. N Engl J Med 2002;346: 1212-20.

[45] Carod-Artal FJ. Neuroschistosomiasis. Expert Rev Anti Infect Ther 2010;8: 1307-18.

[46] Carod-Artal FJ. Neurological complications of Schistosoma infection. Trans R Soc

Trop Med Hyg 2008;102: 107-16.

[47] Scrimgeour EM, Gajdusek DC. Involvement of the central nervous system in Schistosoma mansoni and S. haematobium infection. A review. Brain 1985;108 ( Pt 4): 102338.

[48] Rose MF, Zimmerman EE, Hsu L, Golby AJ, Saleh E, Folkerth RD, Santagata SS, Milner DA, Ramkissoon SH. Atypical presentation of cerebral schistosomiasis four years after exposure to Schistosoma mansoni. Epilepsy Behav Case Rep 2014;2: 80-85.

[49] Hayashi M. Clinical studies on cerebral schistosomiasis japonica in the Philippines. Bull Tokyo Med Dent Univ 1979;26: 287-97.

[50] Chai JY. Paragonimiasis. Handb Clin Neurol 2013;114: 283-96.

[51] Keiser J, Utzinger J. Emerging foodborne trematodiasis. Emerg Infect Dis 2005;11: 1507-14.

[52] Procop GW. North American paragonimiasis (Caused by Paragonimus kellicotti) in the context of global paragonimiasis. Clin Microbiol Rev 2009;22: 415-46.

[53] Higashi K, Aoki H, Tatebayashi K, Morioka H, Sakata Y. Cerebral paragonimiasis. J Neurosurg 1971;34: 515-27.

[54] Kusner DJ, King CH. Cerebral paragonimiasis. Semin Neurol 1993;13: 201-8.

[55] Chen Z, Zhu G, Lin J, Wu N, Feng H. Acute cerebral paragonimiasis presenting as hemorrhagic stroke in a child. Pediatr Neurol 2008;39: 133-6.

[56] Chen J, Chen Z, Lin J, Zhu G, Meng H, Cui G, Wu N, Hu R, Pan J, Zou Y, Feng H. Cerebral paragonimiasis: a retrospective analysis of 89 cases. Clin Neurol Neurosurg 2013;115: 546-51.

[57] Wu JY, Zhang BR, Zhao GH. Cerebral infarction and cranial venous sinus thrombosis caused by paragonimiasis. CNS Neurosci Ther 2013;19: 734-6.

[58] Kong Y, Cho SY, Kang WS. Sparganum infections in normal adult population and epileptic patients in Korea: a seroepidemiologic observation. Korean J Parasitol 1994;32: 8592.

[59] Hong D, Xie H, Zhu M, Wan H, Xu R, Wu Y. Cerebral sparganosis in mainland Chinese patients. J Clin Neurosci 2013;20: 1514-9.

[60] WHO. 2017b. Human African Trypanosomiasis: Epidemiological situation [Online]. Available: http://www.who.int/trypanosomiasis_african/country/en/ [Accessed 5 Feb 2017].

[61] Beghi E, Carpio A, Forsgren L, Hesdorffer DC, Malmgren K, Sander JW, Tomson T, Hauser WA. Recommendation for a definition of acute symptomatic seizure. Epilepsia 2010;51: 671-5.

[62] Mejia R, Nash TE. Corticosteroid withdrawal precipitates perilesional edema around calcified Taenia solium cysts. Am J Trop Med Hyg 2013;89: 919-23.

[63] Chayasirisobhon S, Menoni R, Chayasirisobhon W, Locke GE. Correlation of electroencephalography and the active and inactive forms of neurocysticercosis. Clin Electroencephalogr 1999;30: 9-11.

[64] Pitkänen A. Therapeutic Approaches to Epileptogenesis - Hope on the Horizon. Epilepsia 2010;51: 2-17. 
[65] Engel J. (2013). Seizures and epilepsy, $2^{\text {nd }}$ edition. Available at: http://dx.doi.org/10.1093/med/9780195328547.001.0001[Accessed 5 Feb 2017].

[66] Preidler KW, Riepl T, Szolar D, Ranner G. Cerebral schistosomiasis: MR and CT appearance. AJNR Am J Neuroradiol 1996;17: 1598-600.

[67] Chen Z, Chen J, Miao H, Li F, Feng H, Zhu G. Angiographic findings in 2 children with cerebral paragonimiasis with hemorrhage. J Neurosurg Pediatr 2013;11: 564-7.

[68] Medana IM, Idro R, Newton CR. Axonal and astrocyte injury markers in the cerebrospinal fluid of Kenyan children with severe malaria. J Neurol Sci 2007;258: 93-8.

[69] Dobbie M, Crawley J, Waruiru C, Marsh K, Surtees R. Cerebrospinal fluid studies in children with cerebral malaria: an excitotoxic mechanism? Am J Trop Med Hyg 2000;62: 284-90.

[70] Mturi N, Keir G, Maclennan CA, Ross A, Willis AC, Elford BC, Berkley JA, Newton CR. Cerebrospinal Fluid Studies in Kenyan Children with Severe Falciparum Malaria. Open Trop Med J 2008;1: 56-62.

[71] Kampondeni SD, Potchen MJ, Beare NA, Seydel KB, Glover SJ, Taylor TE, Birbeck GL. MRI findings in a cohort of brain injured survivors of pediatric cerebral malaria. Am J Trop Med Hyg 2013;88: 542-6.

[72] Newton CR, Marsh K, Peshu N, Kirkham FJ. Perturbations of cerebral hemodynamics in Kenyans with cerebral malaria. Pediatr Neurol 1996;15: 41-9.

[73] Toro G, Roman G. Cerebral malaria. A disseminated vasculomyelinopathy. Arch Neurol 1978;35: 271-5.

[74] Sharma P, Garg RK, Verma R, Singh MK, Shukla R. Risk of seizure recurrence in patients of new-onset partial seizure having a solitary cysticercus granuloma of brain or normal neuroimaging. J Neurol Sci 2011;301: 21-6.

[75] Antoniuk SA, Bruck I, Dos Santos LH, Pintarelli VL, Navolar FB, Brackmann PC, Jr., de Morais RL. Seizures associated with calcifications and edema in neurocysticercosis. Pediatr Neurol 2001;25: 309-11.

[76] Nash TE, Pretell J, Garcia HH. Calcified cysticerci provoke perilesional edema and seizures. Clin Infect Dis 2001;33: 1649-53.

[77] Nash TE, Pretell EJ, Lescano AG, Bustos JA, Gilman RH, Gonzalez AE, Garcia HH. Perilesional brain oedema and seizure activity in patients with calcified neurocysticercosis: a prospective cohort and nested case-control study. Lancet Neurol 2008;7: 1099-105.

[78] Fujita M, Mahanty S, Zoghbi SS, Ferraris Araneta MD, Hong J, Pike VW, Innis RB, Nash TE. PET reveals inflammation around calcified Taenia solium granulomas with perilesional edema. PLoS One 2013;8: e74052.

[79] Ooi WW, Wijemanne S, Thomas CB, Quezado M, Brown CR, Nash TE. Short report: A calcified Taenia solium granuloma associated with recurrent perilesional edema causing refractory seizures: histopathological features. Am J Trop Med Hyg 2011;85: 460-3.

[80] Nash TE, Patronas NJ. Edema associated with calcified lesions in neurocysticercosis. Neurology 1999;53: 777-81.

[81] Nash TE, Del Brutto OH, Butman JA, Corona T, Delgado-Escueta A, Duron RM, Evans CA, Gilman RH, Gonzalez AE, Loeb JA, Medina MT, Pietsch-Escueta S, Pretell EJ, Takayanagui OM, Theodore W, Tsang VC, Garcia HH. Calcific neurocysticercosis and epileptogenesis. Neurology 2004;62: 1934-8.

[82] de Souza A, Nalini A, Kovoor JM, Yeshraj G, Siddalingaiah HS, Thennarasu K. Perilesional gliosis around solitary cerebral parenchymal cysticerci and long-term seizure outcome: a prospective study using serial magnetization transfer imaging. Epilepsia 2011;52: 1918-27. 
[83] Pradhan S, Kathuria MK, Gupta RK. Perilesional gliosis and seizure outcome: a study based on magnetization transfer magnetic resonance imaging in patients with neurocysticercosis. Ann Neurol 2000;48: 181-7.

[84] Pradhan S, Kumar R, Gupta RK. Intermittent symptoms in neurocysticercosis: could they be epileptic? Acta Neurol Scand 2003;107: 260-6.

[85] Kihara M, Carter JA, Holding PA, Vargha-Khadem F, Scott RC, Idro R, Fegan GW, de Haan M, Neville BGR, Newton CRJC. Impaired everyday memory associated with encephalopathy of severe malaria: the role of seizures and hippocampal damage. Malaria Journal 2009;8.

[86] de Miranda AS, Brant F, Campos AC, Vieira LB, Rocha NP, Cisalpino D, Binda NS, Rodrigues DH, Ransohoff RM, Machado FS, Rachid MA, Teixeira AL. Evidence for the contribution of adult neurogenesis and hippocampal cell death in experimental cerebral malaria cognitive outcome. Neuroscience 2015;284: 920-33.

[87] Velasco TR, Zanello PA, Dalmagro CL, Araujo D, Jr., Santos AC, Bianchin MM, Alexandre V, Jr., Walz R, Assirati JA, Carlotti CG, Jr., Takayanagui OM, Sakamoto AC, Leite JP. Calcified cysticercotic lesions and intractable epilepsy: a cross sectional study of 512 patients. J Neurol Neurosurg Psychiatry 2006;77: 485-8.

[88] Bianchin MM, Velasco TR, Wichert-Ana L, Alexandre V, Jr., Araujo D, Jr., dos Santos AC, Carlotti CG, Jr., Takayanagui OM, Sakamoto AC. Characteristics of mesial temporal lobe epilepsy associated with hippocampal sclerosis plus neurocysticercosis. Epilepsy Res 2014;108: 1889-95.

[89] Del Brutto OH, Salgado P, Lama J, Del Brutto VJ, Campos X, Zambrano M, Garcia HH. Calcified Neurocysticercosis Associates with Hippocampal Atrophy: A PopulationBased Study. Am J Trop Med Hyg 2014.

[90] Rathore C, Thomas B, Kesavadas C, Radhakrishnan K. Calcified neurocysticercosis lesions and hippocampal sclerosis: potential dual pathology? Epilepsia 2012;53: e60-2.

[91] Bianchin MM, Velasco TR, Coimbra ER, Gargaro AC, Escorsi-Rosset SR, WichertAna L, Terra VC, Alexandre V, Jr., Araujo D, Jr., dos Santos AC, Fernandes RM, Assirati JA, Jr., Carlotti CG, Jr., Leite JP, Takayanagui OM, Markowitsch HJ, Sakamoto AC. Cognitive and surgical outcome in mesial temporal lobe epilepsy associated with hippocampal sclerosis plus neurocysticercosis: a cohort study. PLoS One 2013;8: e60949. [92] Rathore C, Thomas B, Kesavadas C, Abraham M, Radhakrishnan K. Calcified neurocysticercosis lesions and antiepileptic drug-resistant epilepsy: a surgically remediable syndrome? Epilepsia 2013;54: 1815-22.

[93] Gupta RK, Awasthi R, Rathore RK, Verma A, Sahoo P, Paliwal VK, Prasad KN, Pandey CM, Narayana PA. Understanding epileptogenesis in calcified neurocysticercosis with perfusion MRI. Neurology 2012;78: 618-25.

[94] Szklarczyk A, Lapinska J, Rylski M, McKay RD, Kaczmarek L. Matrix metalloproteinase-9 undergoes expression and activation during dendritic remodeling in adult hippocampus. J Neurosci 2002;22: 920-30.

[95] Idro R, Carter JA, Fegan G, Neville BGR, Newton CRJC. Risk factors for persisting neurological and cognitive impairments following cerebral malaria. Arch Dis Child 2006;91: 142-148.

[96] Gupta RK, Awasthi R, Garg RK, Kumar N, Gupta PK, Singh AK, Sahoo P, Paliwal VK, Prasad KN, Pandey CM, Rathore RK. T1-weighted dynamic contrast-enhanced MR evaluation of different stages of neurocysticercosis and its relationship with serum MMP-9 expression. AJNR Am J Neuroradiol 2013;34: 997-1003.

[97] Mehta S, Singh G. Electroclinical characteristics of new-onset seizures associated with neurocysticercosis. Neurol India 2014;62: 159-63. 
[98] Hesdorffer DC, Logroscino G, Cascino G, Annegers JF, Hauser WA. Risk of unprovoked seizure after acute symptomatic seizure: effect of status epilepticus. Ann Neurol 1998;44: 908-12.

[99] Parmar H, Lim SH, Tan NC, Lim CC. Acute symptomatic seizures and hippocampus damage: DWI and MRS findings. Neurology 2006;66: 1732-5.

[100] Henriquez SA, Brett R, Alexander J, Pratt J, Roberts CW. Neuropsychiatric disease and Toxoplasma gondii infection. Neuroimmunomodulation 2009;16: 122-33.

[101] Erttmann KD, Buttner DW, Gallin MY. Molecular cloning, expression, and localization of E1, an Onchocerca volvulus antigen with similarity to brain ankyrin. J Biol Chem 1996;271: 1645-50.

[102] Johnson TP, Tyagi R, Lee PR, et al. Nodding syndrome may be an autoimmune reaction to the parasitic worm Onchocerca volvulus. Sci Transl Med 2017; 9(377): eaaf6953. [103] Snow RW, Bastos de Azevedo I, Lowe BS, Kabiru EW, Nevill CG, Mwankusye S, Kassiga G, Marsh K, Teuscher T. Severe childhood malaria in two areas of markedly different falciparum transmission in east Africa. Acta Trop 1994;57: 289-300.

[104] Rovira-Vallbona E, Moncunill G, Bassat Q, Aguilar R, Machevo S, Puyol L, Quinto L, Menendez C, Chitnis CE, Alonso PL, Dobano C, Mayor A. Low antibodies against Plasmodium falciparum and imbalanced pro-inflammatory cytokines are associated with severe malaria in Mozambican children: a case-control study. Malar J 2012;11: 181. [105] Jayaraman T, Prabhakaran V, Babu P, Raghava MV, Rajshekhar V, Dorny P, Muliyil $\mathrm{J}$, Oommen A. Relative seroprevalence of cysticercus antigens and antibodies and antibodies to Taenia ova in a population sample in south India suggests immunity against neurocysticercosis. Trans R Soc Trop Med Hyg 2011;105: 153-9.

[106] Ngoungou EB, Dulac O, Poudiougou B, Druet-Cabanac M, Dicko A, Traore AM, Coulibaly D, Farnarier G, Tuillas M, Keita MM, Kombila M, Doumbo OK, Preux PM. Epilepsy as a consequence of cerebral malaria in area in which malaria is endemic in Mali, West Africa. Epilepsia 2006;47: 873-879.

[107] Postels DG, Taylor TE, Molyneux M, Mannor K, Kaplan PW, Seydel KB, Chimalizeni YF, Kawaza K, Birbeck GL. Neurologic outcomes in retinopathy-negative cerebral malaria survivors. Neurology 2012;79: 1268-1272.

[108] McGuire W, Hill AV, Allsopp CE, Greenwood BM, Kwiatkowski D. Variation in the TNF-alpha promoter region associated with susceptibility to cerebral malaria. Nature 1994;371: 508-10.

[109] Verma A, Prasad KN, Gupta RK, Singh AK, Nyati KK, Rizwan A, Pandey CM, Paliwal VK. Toll-like receptor 4 polymorphism and its association with symptomatic neurocysticercosis. J Infect Dis 2010;202: 1219-25.

[110] Punsawad C, Maneerat Y, Chaisri U, Nantavisai K, Viriyavejakul P. Nuclear factor kappa B modulates apoptosis in the brain endothelial cells and intravascular leukocytes of fatal cerebral malaria. Malar J 2013;12: 260.

[111] DellaValle B, Hempel C, Kurtzhals JA, Penkowa M. In vivo expression of neuroglobin in reactive astrocytes during neuropathology in murine models of traumatic brain injury, cerebral malaria, and autoimmune encephalitis. Glia 2010;58: 1220-7.

[112] Flegr J. Effects of toxoplasma on human behavior. Schizophr Bull 2007;33: 757-60. [113] Flegr J, Havlicek J, Kodym P, Maly M, Smahel Z. Increased risk of traffic accidents in subjects with latent toxoplasmosis: a retrospective case-control study. BMC Infect Dis 2002;2: 11 .

[114] Yereli K, Balcioglu IC, Ozbilgin A. Is Toxoplasma gondii a potential risk for traffic accidents in Turkey? Forensic Sci Int 2006;163: 34-7.

[115] Kocazeybek B, Oner YA, Turksoy R, Babur C, Cakan H, Sahip N, Unal A, Ozaslan A, Kilic S, Saribas S, Aslan M, Taylan A, Koc S, Dirican A, Uner HB, Oz V, Ertekin C, 
Kucukbasmaci O, Torun MM. Higher prevalence of toxoplasmosis in victims of traffic accidents suggest increased risk of traffic accident in Toxoplasma-infected inhabitants of Istanbul and its suburbs. Forensic Sci Int 2009;187: 103-8.

[116] Jones JL, Kruszon-Moran D, Won K, Wilson M, Schantz PM. Toxoplasma gondii and Toxocara spp. co-infection. Am J Trop Med Hyg 2008;78: 35-9.

[117] Kamuyu G, Bottomley C, Mageto J, Lowe B, Wilkins PP, Noh JC, Nutman TB, Ngugi AK, Odhiambo R, Wagner RG, Kakooza-Mwesige A, Owusu-Agyei S, Ae-Ngibise K, Masanja H, Osier FH, Odermatt P, Newton CR. Exposure to multiple parasites is associated with the prevalence of active convulsive epilepsy in sub-Saharan Africa. PLoS Negl Trop Dis 2014;8: e2908.

[118] Vega R, Pinero D, Ramanankandrasana B, Dumas M, Bouteille B, Fleury A, Sciutto E, Larralde C, Fragoso G. Population genetic structure of Taenia solium from Madagascar and Mexico: implications for clinical profile diversity and immunological technology. Int $\mathbf{J}$ Parasitol 2003;33: 1479-85.

[119] Gondorf F, Berbudi A, Buerfent BC, Ajendra J, Bloemker D, Specht S, Schmidt D, Neumann AL, Layland LE, Hoerauf A, Hubner MP. Chronic filarial infection provides protection against bacterial sepsis by functionally reprogramming macrophages. PLoS Pathog 2015;11: e1004616.

[120] Konig R, Nassri A, Meindl M, Matuja W, Kidunda AR, Siegmund V, Bretzel G, Loscher T, Jilek-Aall L, Schmutzhard E, Winkler AS. The role of Onchocerca volvulus in the development of epilepsy in a rural area of Tanzania. Parasitology 2010;137: 1559-68.

[121] Boulle C, Dema F, Njamnshi AK, Mengnjo M, Siewe J, Tatah GY, Zoung-Kanyi Bissek AC, Suykerbuyk P, Pion S, Lenou-Nanga C, Nana-Djeunga HC, Kamgno J, Chesnais C, Boussinesq M, Colebunders R. Epilepsy prevalence and cohort age shift: Evidence for the benefit of ivermectine mass drug administration on onchocerciasis-associated epilepsy in th Mbam Valley, Cameroon. In: First International Workshop on onchocerciasis-associated epilepsy. Antwerp, Belgium; 2017. 